\title{
A Modified MTS Proliferation Assay for Suspended Cells to Avoid the Interference by Hydralazine and $\beta$-Mercaptoethanol
}

Yutang Wang, ${ }^{1}$ Dinh Tam Nguyen, ${ }^{1}$ Guang Yang, Jack Anesi, ${ }^{1}$ Jason Kelly, ${ }^{1,3}$ Zhonglin Chai, ${ }^{4}$ Fahima Ahmady, Fadi Charchar, and Jonathan Golledge ${ }^{5,6}$

${ }^{1}$ Discipline of Life Sciences, School of Science, Psychology and Sport, Federation University Australia, Ballarat, Australia.

${ }^{2}$ Department of Gerontology, the First Affiliated Hospital of Shandong First Medical University, Jinan, China.

${ }^{3}$ Fiona Elsey Cancer Research Institute, Ballarat, Australia. ${ }^{4}$ Department of Diabetes, Central Clinical School, Monash University, Melbourne, Australia

${ }^{5}$ Queensland Research Centre for Peripheral Vascular Disease, College of Medicine and Dentistry, James Cook University, Townsville, Australia.

${ }^{6}$ Department of Vascular and Endovascular Surgery, The Townsville University Hospital, Townsville, Australia.

\section{ABSTRACT}

The 3-(4,5-dimethylthiazol-2-yl)-5-(3-carboxymethoxyphenyl)2-(4-sulfophenyl)-2H-tetrazolium (MTS) assay is one of the most commonly used tests of cell proliferation. Hydralazine has been reported to interfere with the performance of the MTS assay when used on adherent cells. This study aimed to investigate whether hydralazine interferes with the performance of the MTS assay on suspended cells. THP-1 (a monocytic leukemia cell line) cells were cultured in the presence or absence of hydralazine $(0,10,50,100$, and $500 \mu \mathrm{M})$ for 2 or $24 \mathrm{~h}$. Cell numbers were analyzed using the MTS, trypan blue exclusion, or microscopic assays. A modified version of the standard MTS assay was established by centrifuging the cells and replacing the test medium with fresh culture medium immediately before the addition of the MTS reagent. Culture of THP-1 cells with hydralazine at concentrations of 50,100 , and $500 \mu \mathrm{M}$ for $2 \mathrm{~h}$ increased absorbance $(p<0.001)$ in the standard MTS assay, whereas both the trypan blue exclusion assay and microscopy suggested no change in cell numbers. Culture of THP-1 cells with 100 and $500 \mu m$ hydralazine for $24 \mathrm{~h}$ increased absorbance $(p<0.05)$ in the standard MTS assay; however, trypan blue exclusion and microscopy suggested a decrease in cell numbers. In a cell-free system, hydralazine (100 and $500 \mu \mathrm{M})$ increased absorbance in a time- and concentrationdependent manner. The modified MTS assay produced results consistent with trypan blue exclusion and microscopy using THP-1 cells. In addition, the modified MTS assay produced reliable results when K562 and Jurkat cells were incubated with hydralazine or $\beta$-mercaptoethanol ( $\beta M E)$. In conclusion, a simple modification of the standard MTS assay overcame the interference of hydralazine and $\beta M E$ when assessing suspended cells.

Keywords: cytotoxicity, hydralazine, MTS proliferation assay, suspension cells

\section{INTRODUCTION}

$\mathrm{n}$ viable cells, NAD(P)H-dependent oxidoreductase enzymes expressed in mitochondria are capable of converting tetrazolium into colored formazan, ${ }^{1-7}$ proportional to the metabolic activity of mitochondrial enzymes in live cells. The amount of produced formazan can be quantified through absorbance measured by a spectrophotometer and used to estimate the cell numbers. The 3-(4,5-dimethylthiazol-2-yl)-5-(3-carboxymethoxyphenyl)2-(4-sulfophenyl)-2H-tetrazolium (MTS) assay relies on this reaction to assay cell numbers. ${ }^{1}$ The standard protocol for the MTS assay is very simple. The MTS reagent is directly added to the cultured cells and the absorbance measured after a defined period of incubation.

Hydralazine is an antihypertensive drug that is commonly investigated in heart failure, ${ }^{8}$ cancer, ${ }^{9,10}$ and blood pressure research. ${ }^{11}$ It was recently reported that hydralazine interferes with the performance of MTS assay on adherent cells, ${ }^{12}$ and a simple modification of the standard protocol avoids this interference. ${ }^{12}$ A number of cell lines are cultured in suspension. The effect of hydralazine on assays of suspended cells has not been previously investigated. This study aimed to examine the effect of hydralazine on the MTS assay of THP-1 (a monocytic leukemia cell line), K562, and Jurkat cells, three commonly used cell lines derived from leukemia. A modified version of the standard MTS assay protocol was developed that included two additional steps, namely centrifuging the suspended cells 
in a 96-well plate and then aspirating and replacing the test medium with fresh culture medium immediately before the addition of the MTS reagent.

This modified MTS protocol advanced a previously modified protocol $^{12}$ of aspirating and replacing the culture medium by adding an extra step of centrifuging the cells. The current protocol overcame the interference with the MTS assay by various testing compounds when suspended cells were used.

\section{MATERIALS AND METHODS}

\section{Cell Culture}

The THP-1, K562, and Jurkat cells were cultured in Roswell Park Memorial Institute 1640 medium (RPMI1640) or Dulbecco's modified Eagle's medium as previously described. ${ }^{12,13}$

\section{MTS Assay}

The standard protocol. This was described previously. ${ }^{12}$ In brief, cells were seeded at a concentration of $2 \times 10^{5}$ cells $/ \mathrm{mL}$, $150 \mu \mathrm{L} /$ well into 96-well flat bottomed tissue culture plates in eight replicates. After the cells were cultured with hydralazine $(0,10,50,100$, and $500 \mu \mathrm{M})$, or $\beta$-mercaptoethanol $(\beta \mathrm{ME})$ $(0,100$, and $500 \mu \mathrm{M})$, or phosphate-buffered saline (PBS) for the specified time, $15 \mu \mathrm{L}$ of MTS reagent was added into each well and the absorbance was assessed at $490 \mathrm{~nm}$ with a microplate reader after 2-h incubation with MTS. ${ }^{12,14}$

The modified protocol. This was based upon a recently published modified protocol. ${ }^{12}$ In that protocol that was designed for adherent cells, the culture medium in the well was aspirated and replaced with $150 \mu \mathrm{L}$ fresh, prewarmed standard cell medium immediately before the addition of the $15 \mu \mathrm{L}$ of MTS reagent. ${ }^{12}$ The current modified protocol, which was designed for suspended cells, added an extra step to that protocol, that is, the cells in the 96-well plate were centrifuged at $300 \mathrm{~g}$ for 5 min before the culture medium in the well was aspirated.

\section{Trypan Blue Exclusion Assay}

About $150 \mu \mathrm{L}$ of THP- $1\left(2 \times 10^{5} / \mathrm{mL}\right)$ cells were placed in a flatbottom 96-well plate for $24 \mathrm{~h}$. Three microliters of PBS or various concentrations of hydralazine were added to give a final concentration of $0,10,50,100$, and $500 \mu \mathrm{M}$ of hydralazine. Two or $24 \mathrm{~h}$ later, $10 \mu \mathrm{L}$ of cells and $10 \mu \mathrm{L}$ of trypan blue were mixed and cell numbers were counted using an automated cell counter (Thermo Fisher Scientific, Melbourne, VIC, Australia). ${ }^{12,14}$

\section{Imaging Using Light Microscopy}

Images of the cell culture plates were captured using a contrast phase microscope (Thermo Fisher Scientific). ${ }^{12}$

\section{Statistical Analysis}

SPSS (version 25) was used for all statistical analyses. Data were presented as mean \pm standard deviation. Comparisons of mean values were performed by one-way analysis of variance with Bonferroni post hoc test. Differences were considered to be statistically significant at $p<0.05 .{ }^{12}$

\section{RESULTS}

Overestimate of Live Cell Numbers Using the Standard MTS Assay Protocol in THP-1 Cells

In the cells incubated with hydralazine for $2 \mathrm{~h}$, the results obtained from the standard MTS assay protocol suggested that hydralazine concentration-dependently increased cell numbers (Fig. 1A). Incubation with 50, 100, and $500 \mu \mathrm{M}$ hydralazine for $2 \mathrm{~h}$ appeared to increase the cell number by $2.6,4.5$, and 11.4 times that of the control ( $0 \mu \mathrm{M}$ hydralazine) (Fig. 1A). Both the trypan blue exclusion assay (Fig. 1B) and the observations using a light microscope (Fig. 1C) suggested that the cell numbers in each group were similar, suggesting that the standard MTS protocol did not accurately estimate the cell numbers.

Similar findings were obtained from THP-1 cells incubated with hydralazine for $24 \mathrm{~h} \mathrm{(Fig.} \mathrm{2).} \mathrm{The} \mathrm{standard} \mathrm{MTS} \mathrm{assay} \mathrm{pro-}$ tocol suggested that incubation with 100 and $500 \mu \mathrm{M}$ of hydralazine for $24 \mathrm{~h}$ increased the cell number to 1.1 and 2.7 times that of the control ( $0 \mu \mathrm{M}$ hydralazine) (Fig. 2A). These findings contradicted the results from the trypan blue exclusion assay (Fig. 2B), which suggested that both 100 and $500 \mu \mathrm{M}$ hydralazine decreased the live cell numbers. The results from the trypan blue exclusion assay were confirmed by observations using a light microscope (Fig. 2C), which showed that both concentrations of hydralazine (100 and $500 \mu \mathrm{M})$ caused cell death.

\section{Direct Reaction of MTS with Hydralazine \\ in a Cell-Free System}

The possibility of a direct reaction between MTS and hydralazine was then investigated. In the absence of cells, the absorbance of MTS significantly increased in the presence of hydralazine in a time- and concentration-dependent manner (Fig. 3). This suggested the direct reaction of the colorless MTS with hydralazine to produce a colored compound. The reaction was detectable within 5 min of incubating MTS with hydralazine and reached a plateau around $3 \mathrm{~h}$ (Fig. 3).

A Modified MTS Protocol Can Accurately Measure the Live Cell Number of THP-1 Cells Incubated with Hydralazine

The manufacturer's instruction recommends directly adding MTS to the wells containing cells. Given that hydralazine can directly react with MTS, the assay protocol was modified by centrifuging the cells in the 96-well plate at $300 \mathrm{~g}$ for $5 \mathrm{~min}$ 


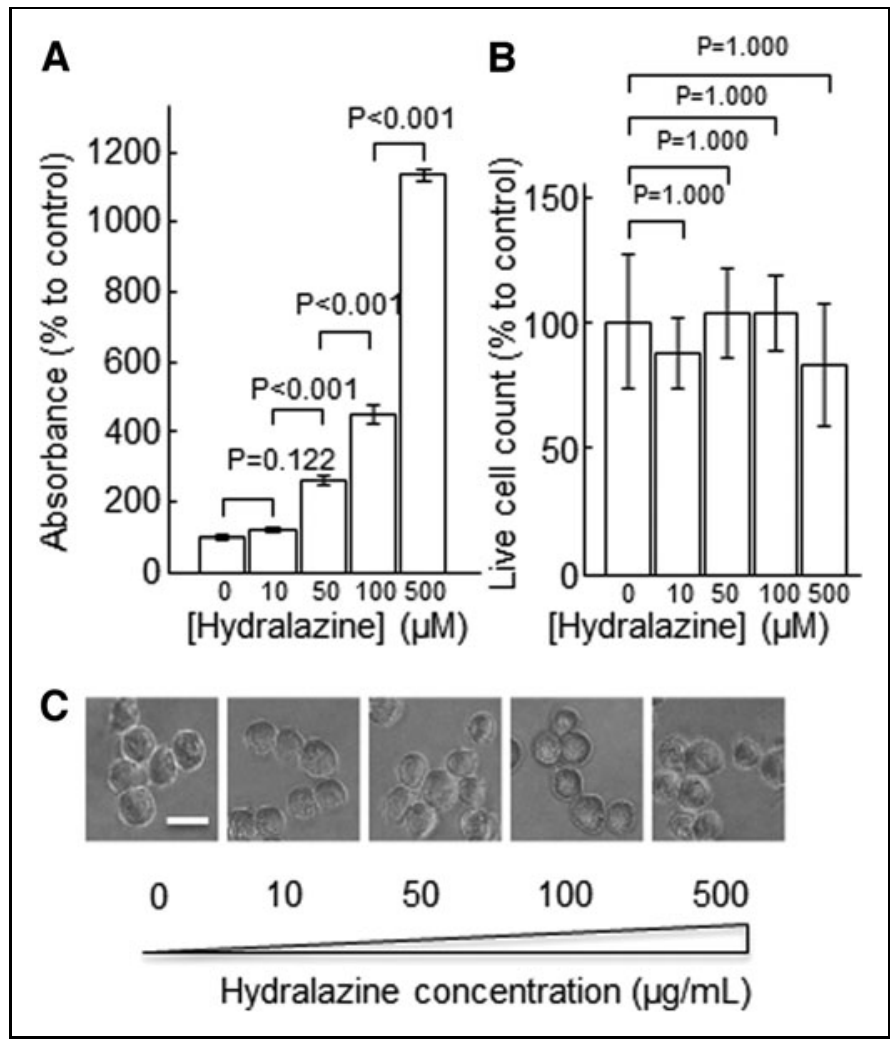

Fig. 1. Effects of incubating hydralazine with THP-1 cells for $2 \mathrm{~h}$ as assessed by different assays. About $150 \mu \mathrm{L}$ of THP-1 cells $\left(2 \times 10^{5} /\right.$ $\mathrm{mL}$ ) were placed in each well of a flat-bottom 96-well plate for $24 \mathrm{~h}$. Three microliters of PBS or $3 \mu \mathrm{L}$ of various concentrations of hydralazine were added to give final concentrations of $0,10,50,100$, and $500 \mu \mathrm{M}$ of hydralazine in the wells for $2 \mathrm{~h}$. (A) Findings of the standard MTS assay. Fifteen microliters of MTS was added after the 2 -h incubation with hydralazine and absorbance was measured using a plate reader $2 \mathrm{~h}$ after the addition of MTS. The absorbance value in the well containing the medium plus MTS in the absence of cells was regarded as background and subtracted from the absorbance of other wells. The absorbance in the control group (o $\mu \mathrm{M}$ hydralazine) was regarded as $100 \%(N=8)$. Error bars represent standard deviation. (B) The findings of the trypan blue exclusion assay after incubating THP-1 cells with hydralazine for $2 \mathrm{~h}$. The cell number in the control group (o $\mu \mathrm{M}$ hydralazine) was regarded as $100 \%(N=8)$. Error bars represent standard deviation. Statistical comparisons were performed using one-way ANOVA followed by Bonferroni post hoc tests. (C) Representative images of THP-1 after incubation with hydralazine for $2 \mathrm{~h}$. Scale bar $=20 \mu \mathrm{m}$. ANOVA, analysis of variance; MTS, 3-(4,5-dimethylthiazol-2-yl)-5-(3carboxymethoxyphenyl)-2-(4-sulfophenyl)-2H-tetrazolium.

and replacing the used culture medium in the wells with prewarmed fresh culture medium immediately before the addition of MTS. Using the modified MTS assay protocol, the incubation of THP- 1 cells with hydralazine for $2 \mathrm{~h}$ did not appear to affect the absorbance (Fig. 4A), consistent with the results of the trypan blue exclusion assay (Fig. 1B) and with the observations from the light microscope (Fig. 1C). The re-

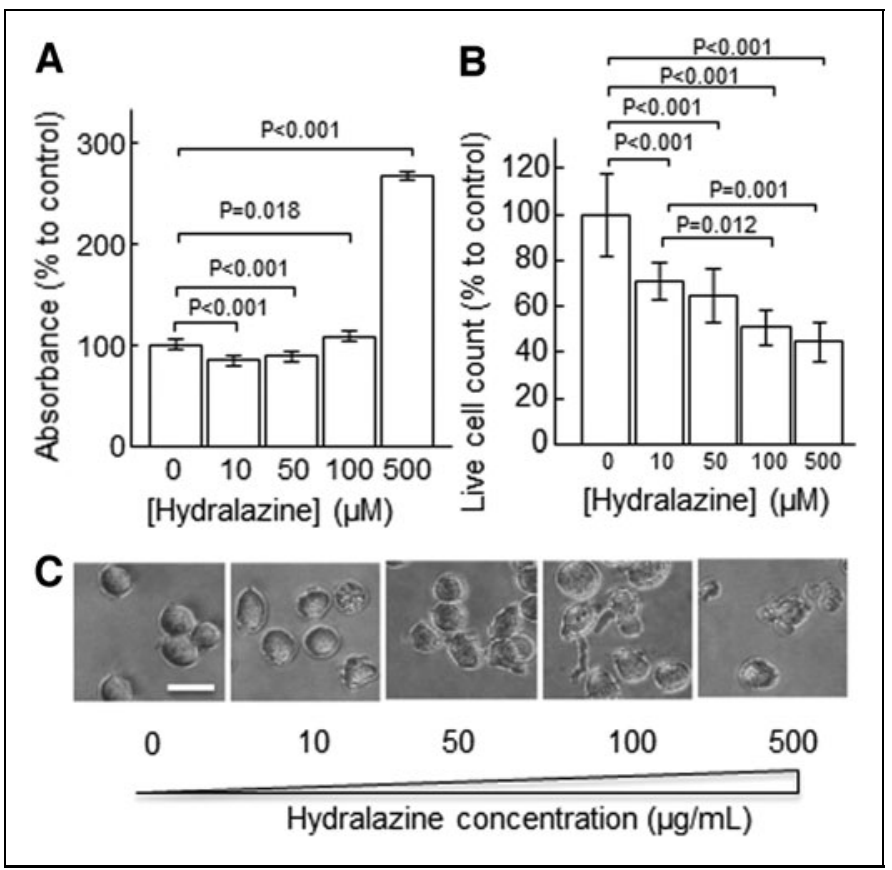

Fig. 2. Effects of incubating hydralazine with THP-1 cells for $24 \mathrm{~h}$ as assessed by different assays. About $150 \mu \mathrm{L}$ of THP-1 cells $\left(2 \times 10^{5} / \mathrm{mL}\right)$ were placed in each well of a flat-bottom 96 -well plate for $24 \mathrm{~h}$. Three microliters of PBS or $3 \mu \mathrm{L}$ of various concentrations of hydralazine were added to give final concentrations of $0,10,50$, 100 , and $500 \mu \mathrm{M}$ of hydralazine in the wells for $24 \mathrm{~h}$. (A) Findings of the standard MTS assay. Fifteen microliters of MTS was added after the $24^{-h}$ incubation with hydralazine and absorbance was measured using a plate reader $2 \mathrm{~h}$ after the addition of MTS. The absorbance value in the well containing the medium plus MTS in the absence of cells was regarded as background and subtracted from the absorbance of other wells. The absorbance in the control group (o $\mu \mathrm{M}$ hydralazine) was regarded as $100 \%(N=8)$. Error bars represent standard deviation. (B) The findings of the trypan blue exclusion assay after incubating THP-1 cells with hydralazine for $24 \mathrm{~h}$. The cell number in the control group (o $\mu \mathrm{M}$ hydralazine) was regarded as $100 \%(N=8)$. Error bars represent standard deviation. Statistical comparisons were performed using one-way ANOVA followed by Bonferroni post hoc tests. (C) Representative images of THP-1 after incubation with hydralazine for $24 \mathrm{~h}$. Scale bar $=20 \mu \mathrm{m}$. PBS, phosphate-buffered saline.

sults from the modified MTS assay protocol suggested that incubation of THP- 1 cells with $10,50,100$, and $500 \mu \mathrm{M}$ of hydralazine for $24 \mathrm{~h}$ significantly decreased cell numbers in a concentration-dependent manner (Fig. 4B), which was consistent with the results from the trypan blue exclusion assay (Fig. 2B) and the microscopy observations (Fig. 2C).

Modified MTS Protocol Can Accurately Measure the Live Cell Number of K562 and Jurkat Cells Incubated with Hydralazine or $\beta \mathrm{ME}$

Another suspended cell line, that is, K562, was used to validate the modified MTS assay protocol (Fig. 5). The 


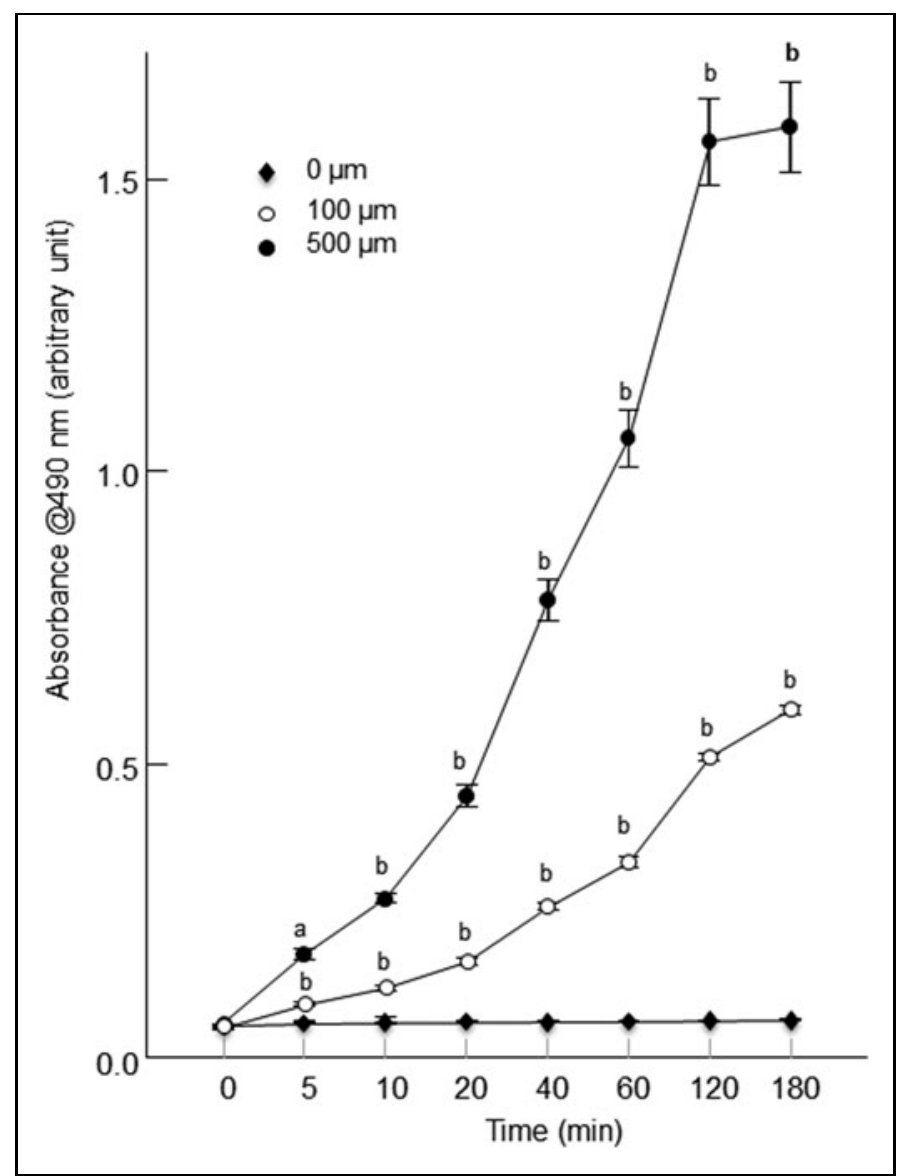

Fig. 3. The reactivity of hydralazine with MTS reagent. Three microliters of PBS or various concentrations of hydralazine were added to $150 \mu \mathrm{L}$ of PBS in wells of a flat-bottom 96-well plate to give final concentrations of 0,100 , and $500 \mu \mathrm{M}$ of hydralazine. Fifteen microliters of MTS was then added and absorbance was measured using a plate reader at $0,5,10,20,40,60,120$, and 180 min after addition of MTS $(N=4)$. Error bars represent standard deviation. Statistical comparisons were performed using one-way ANOVA followed by Bonferroni post hoc tests. ${ }^{\mathrm{a}} p<0.05,{ }^{b} p<0.001$ compared with the absorbance of the same concentration of hydralazine at o min.

standard MTS assay protocol overestimated cell numbers in the presence of hydralazine (Fig. 5A) or $\beta \mathrm{ME}$ (Fig. 5C). The results from the modified MTS assay protocol correctly showed that the cell numbers in each group were similar (Fig. 5B, D). Similar results were obtained in Jurkat cells (Fig. 6).

\section{DISCUSSION}

This study reports a simple two-step modification of the standard MTS assay protocol that overcame the interference of hydralazine when assaying suspended cells. As has been

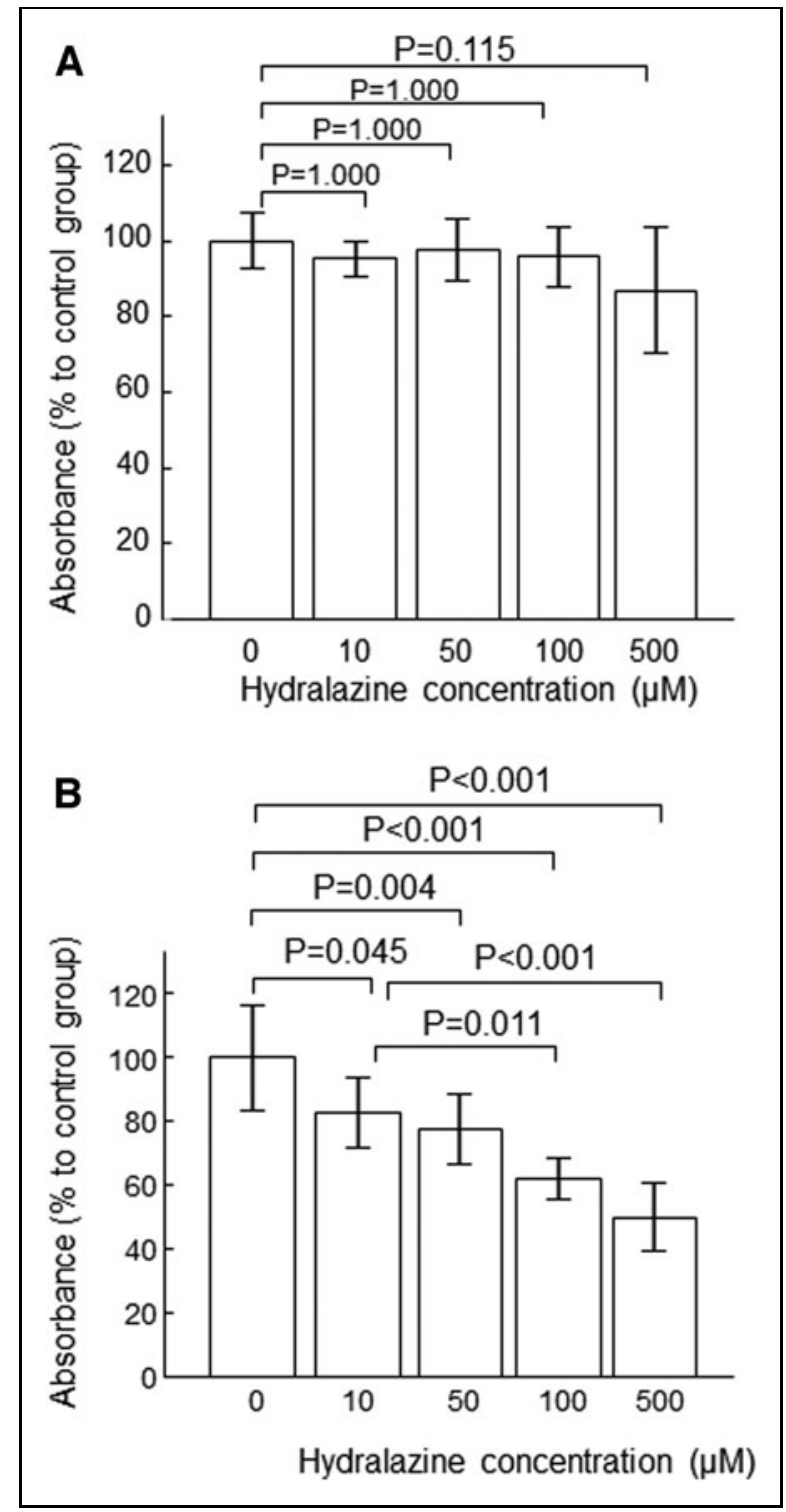

Fig. 4. Effects of incubating hydralazine with THP-1 cells for 2 or $24 \mathrm{~h}$ as assessed by the modified MTS assay protocol. About $150 \mu \mathrm{L}$ of THP-1 cells $\left(2 \times 10^{5} / \mathrm{mL}\right)$ were placed in each well of a flat-bottom 96-well plate for $24 \mathrm{~h}$. Three microliters of PBS or various concentrations of hydralazine were added to give final concentrations of $0,10,50,100$, and $500 \mu \mathrm{M}$ of hydralazine in the wells for $2 \mathrm{~h}(\mathrm{~A})$ or $24 \mathrm{~h}(\mathrm{~B})$. Then the cells in the 96-well plate were centrifuged at $300 \mathrm{~g}$ for $5 \mathrm{~min}$ and medium was aspirated and replaced with prewarm $\left(37^{\circ} \mathrm{C}\right) 150 \mu \mathrm{L}$ culture medium. Fifteen microliters of MTS was then added and absorbance was measured using a plate reader $2 \mathrm{~h}$ after the addition of MTS. The absorbance value in the well containing the medium plus MTS in the absence of cells was regarded as background and subtracted from the absorbance of other wells. The absorbance in the control group (o $\mu \mathrm{M}$ hydralazine) was regarded as $100 \%(N=8)$. Error bars represent standard deviation. Statistical comparisons were performed using one-way ANOVA followed by Bonferroni post hoc tests. 


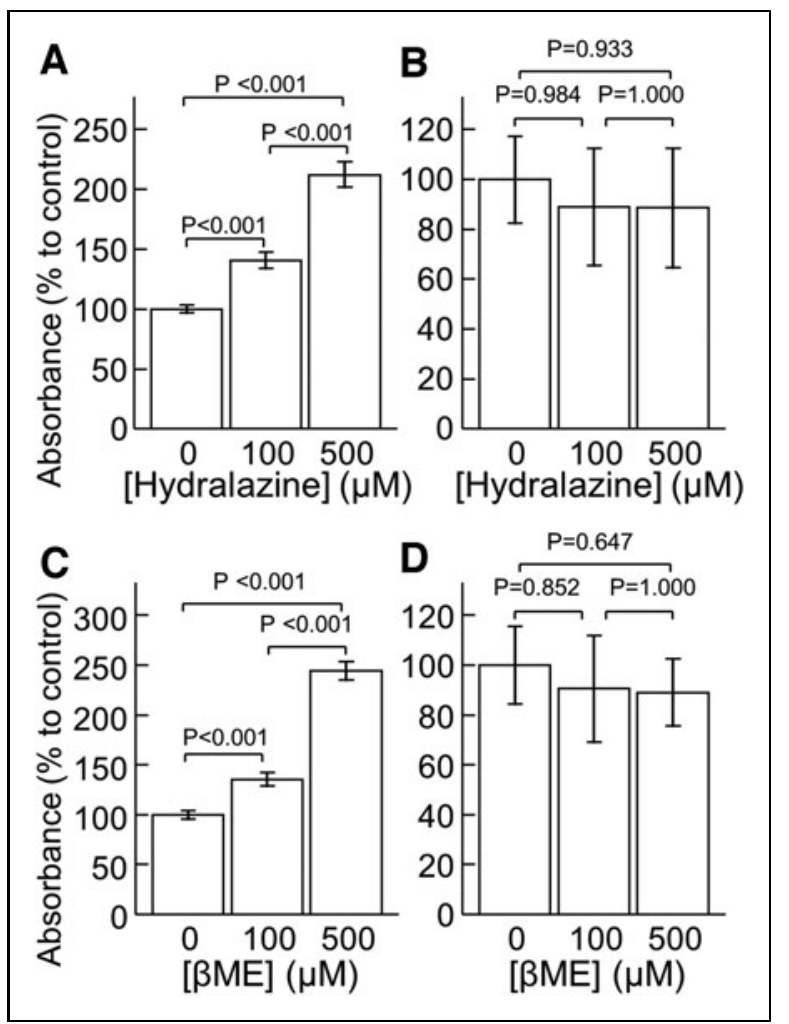

Fig. 5. Effects of hydralazine or $\beta M E$ on MTS assay using $\mathrm{K}_{562}$ cells as assessed by the standard or modified MTS assay protocols. About $150 \mu \mathrm{L}$ of $\mathrm{K}_{5} 62$ cells $\left(2 \times 10^{5} / \mathrm{mL}\right)$ were placed in each well of a flat-bottom 96-well plate for $24 \mathrm{~h}$. Three microliters of PBS or various concentrations of hydralazine (A, B) or $\beta M E(C, D)$ were added to give final concentrations of 0,100 , and $500 \mu \mathrm{M}$. Immediately after the addition of hydralazine or $\beta M E, 15 \mu \mathrm{L}$ of MTS was then added to cells in (A, C) (the standard MTS protocol); or the cells in (B, D) were centrifuged at $300 \mathrm{~g}$ for $5 \mathrm{~min}$ and medium was aspirated and replaced with prewarm $150 \mu \mathrm{L}$ culture medium followed by addition of $15 \mu \mathrm{L}$ of MTS (the modified MTS protocol). Absorbance was measured using a plate reader $1.5 \mathrm{~h}$ after the addition of MTS. The absorbance value in the well containing the medium plus MTS in the absence of cells was regarded as background and subtracted from the absorbance of other wells. The absorbance in the control group (o $\mu \mathrm{M}$ hydralazine or o $\mu \mathrm{M} \beta \mathrm{ME}$ ) was regarded as $100 \%(N=8)$. Error bars represent standard deviation. Statistical comparisons were performed using oneway ANOVA followed by Bonferroni post hoc tests. $\beta \mathrm{ME}$, $\beta$ mercaptoethanol.

previously reported in adherent cells (vascular smooth muscle cells), ${ }^{12}$ a discrepancy in the findings of the standard MTS assay protocol and the trypan blue exclusion and microscopic assays was found. A simple modification of the MTS assay protocol, involving centrifuging the suspended cells and replacing the used culture medium immediately before the addition of the MTS reagent was established. The results from the modified MTS assay protocol were in

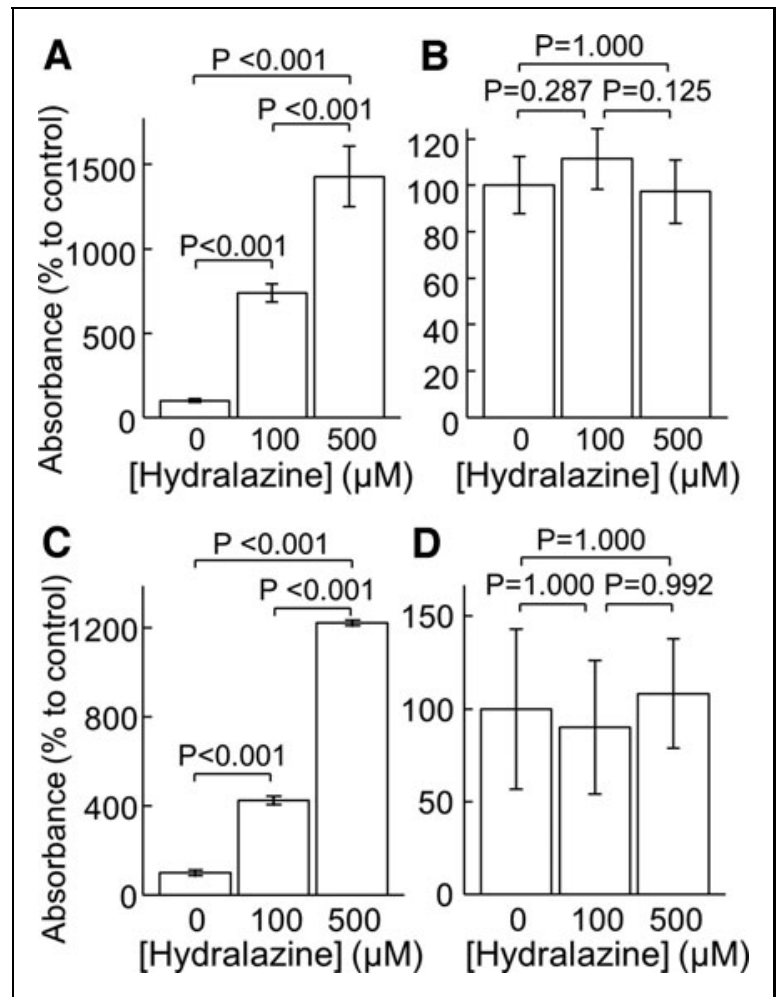

Fig. 6. Effects of hydralazine on MTS assay using Jurkat cells as assessed by the standard or modified MTS assay protocols. Jurkat cells were culture in RPMI (A, B) or DMEM medium (C, D). About $150 \mu \mathrm{L}$ of cells $\left(2 \times 10^{5} / \mathrm{mL}\right)$ were placed in each well of a flat-bottom 96-well plate for $24 \mathrm{~h}$. Three microliters of PBS or various concentrations of hydralazine were added to give final concentrations of 0,100 , and $500 \mu \mathrm{M}$. Immediately after the addition of hydralazine, $15 \mu \mathrm{L}$ of MTS was then added to cells in (A, C) (the standard MTS protocol); or the cells in (B, D) were centrifuged at $300 \mathrm{~g}$ for $5 \mathrm{~min}$ and medium was aspirated and replaced with $150 \mu \mathrm{L}$ of prewarm RPMI (B) or DMEM medium (D) followed by addition of $15 \mu \mathrm{L}$ of MTS (the modified MTS protocol). Absorbance was measured using a plate reader $1.5 \mathrm{~h}$ after the addition of MTS. The absorbance value in the well containing the medium plus MTS in the absence of cells was regarded as background and subtracted from the absorbance of other wells. The absorbance in the control group (o $\mu \mathrm{M}$ hydralazine) was regarded as $100 \%(N=8)$. Error bars represent standard deviation. Statistical comparisons were performed using one-way ANOVA followed by Bonferroni post hoc tests. DMEM, Dulbecco's modified Eagle's medium; RPMI: Roswell Park Memorial Institute medium.

agreement with the results from both the trypan blue exclusion and microscopic assays.

Hydralazine is a reducing reagent that can reduce many oxidizing compounds. ${ }^{15,16}$ The current report found that a reaction between hydralazine and the MTS reagent occurred in a time-dependent manner and was completed around $3 \mathrm{~h}$ after mixing the two compounds. It was recently reported that the reaction between $100 \mu \mathrm{M}$ hydralazine and the MTS reagent completed within $2 \mathrm{~h}^{12}$ The reaction medium in the 
previous report was culture medium with 10\% fetal bovine serum. ${ }^{12}$ The reaction medium used in this study was PBS. The quicker reaction rate in the previous report is likely owing to components of fetal bovine serum facilitating the reaction between hydralazine and the MTS reagent.

In the presence of THP-1 cells, the standard MTS assay protocol suggested that incubation with $10-50 \mu \mathrm{M}$ of hydralazine for $24 \mathrm{~h}$ decreased the cell number, whereas incubation with 100-500 $\mu \mathrm{M}$ of hydralazine for $24 \mathrm{~h}$ increased cell number. Both the trypan blue exclusion assay and microscopic observations suggested that incubation with $10-$ $500 \mu \mathrm{M}$ of hydralazine for $24 \mathrm{~h}$ decreased cell numbers. The false results of the standard MTS assay at both 100 and $500 \mu \mathrm{M}$ for $24 \mathrm{~h}$ may be because of the inability of the cultured cells to completely absorb and metalize the large amounts of hydralazine within $24 \mathrm{~h}$. However, when hydralazine was used at $10 \mu \mathrm{M}$ or $50 \mu \mathrm{M}$ for $24 \mathrm{~h}$, the cells may be able to metabolize the hydralazine, and therefore hydralazine when applying at 10 or $50 \mu \mathrm{M}$ for $24 \mathrm{~h}$ did not interfere with the standard MTS assay.

The results from the modified MTS assay were in good agreement with those from the trypan blue exclusion assay, suggesting that the modified MTS assay is a good alternative method to the trypan blue exclusion assay. The experiment of $24 \mathrm{~h}$ preincubation of THP- 1 cells with hydralazine showed that the readings of the modified MTS assay were slightly higher $(\sim 10 \%)$ compared with the trypan blue exclusion assay. This difference could be because of the difference in measurement mechanism: the trypan blue exclusion assay relies on cell membrane integrity, whereas the MTS assay relies on $\mathrm{NAD}(\mathrm{P}) \mathrm{H}$-dependent oxidoreductase activity inside cells. It is possible that immediately after cells lose their member integrity, a small proportion of the NAD(P)Hdependent oxidoreductase may be still active, resulting in a slightly higher reading in the MTS assay. However, the possibility of a small degree of reversible cytotoxicity of hydralazine during the 2-h incubation with the MTS reagent cannot be excluded.

One limitation of the modified MTS protocol is that it depends on the availability of a plate centrifuge. To avoid inaccurate result, supplementation of the MTS assay with other assays such as the trypan blue exclusion assay, flow cytometry, and microscopic observations is recommended. ${ }^{17}$ In addition, this study only tested a limited number of cell lines and interfering compounds. Whether the modified MTS assay applies to other suspended cell lines or other interfering compounds needs to be investigated in the future.
In summary, this study suggests an important limitation of the standard MTS assay protocol when working with suspended cells. A two-step modification of the standard protocol rectifies this problem and results in accurate cell number estimation.

\section{DISCLOSURE STATEMENT}

No competing financial interests exist.

\section{FUNDING INFORMATION}

This work was funded by grants from the National Health and Medical Research Council of Australia (1062671). J.G. holds a Practitioner Fellowship from the National Health and Medical Research Council of Australia (NHMRC; 1117061) and a Senior Clinical Research Fellowship from the Queensland Government, Australia.

\section{REFERENCES}

1. Arab-Bafrani Z, Shahbazi-Gahrouei D, Abbasian M, Fesharaki M: Multiple MTS assay as the alternative method to determine survival fraction of the irradiated HT-29 colon cancer cells. J Med Signals Sens 2016;6:112116.

2. Price $P$, McMillan TJ: Use of the tetrazolium assay in measuring the response of human tumor cells to ionizing radiation. Cancer Res 1990;50:13921396.

3. Carmichael J, DeGraff WG, Gazdar AF, Minna JD, Mitchell JB: Evaluation of a tetrazolium-based semiautomated colorimetric assay: assessment of chemosensitivity testing. Cancer Res 1987;47:936-942.

4. Ganapathy-Kanniappan $S_{1}$ Geschwind JF, Kunjithapatham $R_{1}$ et al:: The pyruvic acid analog 3-bromopyruvate interferes with the tetrazolium reagent MTS in the evaluation of cytotoxicity. Assay Drug Dev Technol 2010; 8:258-262.

5. Wang $Z$, Wang $P$, Cao $L$, et al: Long intergenic non-coding RNA 01121 promotes breast cancer cell proliferation, migration, and invasion via the miR-150-5p/HMGA2 axis. Cancer Manag Res 2019;11:1085910870.

6. Hua $R$, Pei $Y, G u$, Sun $Y$, He $Y$ : Antitumor effects of flavokawain-B flavonoid in gemcitabine-resistant lung cancer cells are mediated via mitochondrial-mediated apoptosis, ROS production, cell migration and cell invasion inhibition and blocking of PI3K/AKT Signaling pathway. J Buon 2020; 25:262-267.

7. Cory AH, Owen TC, Barltrop JA, Cory JG: Use of an aqueous soluble tetrazolium/ formazan assay for cell growth assays in culture. Cancer Commun 1991;3:207212.

8. Taylor AL, Ziesche $S$, Yancy $C$, et al:: Combination of isosorbide dinitrate and hydralazine in blacks with heart failure. N Engl J Med 2004;351:20492057.

9. Graça I, Sousa EJ, Costa-Pinheiro P, et al:: Anti-neoplastic properties of hydralazine in prostate cancer. Oncotarget 2014;5:5950-5964.

10. Bauman J, Shaheen $M_{1}$ Verschraegen $C_{F}$, et al:: A phase I protocol of hydralazine and valproic acid in advanced, previously treated solid cancers. Trans/ Oncol 2014;7:349-354. 
WANG ET AL.

11. Sridharan K, Sequeira RP: Drugs for treating severe hypertension in pregnancy: a network meta-analysis and trial sequential analysis of randomized clinical trials. Br J Clin Pharmacol 2018;84:1906-1916.

12. Wang $Y$, Nguyen DT, Yang $G$, et al.: An improved 3-(4,5-dimethylthiazol-2-yl)5-(3-carboxymethoxyphenyl)-2-(4-sulfophenyl)-2H-tetrazolium proliferation assay to overcome the interference of hydralazine. Assay Drug Dev Technol 2020;18:379-384.

13. Wang $Y$, Liu $H$, McKenzie $G$, et al:: Kynurenine is an endotheliumderived relaxing factor produced during inflammation. Nat Med 2010;16: 279-285.

14. Wang $P$, Henning SM, Heber D: Limitations of MTT and MTS-based assays for measurement of antiproliferative activity of green tea polyphenols. PLOS One 2010;5:e10202.

15. Burcham PC: Carbonyl scavengers as pharmacotherapies in degenerative disease: Hydralazine repurposing and challenges in clinical translation. Biochem Pharmacol 2018;154:397-406.

16. Daiber $A$, Oelze $M$, Coldewey $M$, et al:: Hydralazine is a powerful inhibitor of peroxynitrite formation as a possible explanation for its beneficial effects on prognosis in patients with congestive heart failure. Biochem Biophys Res Commun 2005;338:1865-1874.

17. Stepanenko AA, Dmitrenko W: Pitfalls of the MTT assay: direct and off-target effects of inhibitors can result in over/underestimation of cell viability. Gene 2015;574:193-203.
Address correspondence to:

Yutang Wang, PhD

Discipline of Life Sciences

School of Science, Psychology and Sport

Federation University Australia

PO Box 663, University Drive

Ballarat

VIC 3350

Australia

E-mail: yutang.wang@ federation.edu.au

\section{Abbreviations Used}

$\beta M E=\beta$-mercaptoethanol

ANOVA $=$ analysis of variance

MTS = 3-(4,5-dimethylthiazol-2-yl)-5-(3-carboxymethoxyphenyl)2-(4-sulfophenyl)-2H-tetrazolium

$\mathrm{PBS}=$ phosphate-buffered saline 